\title{
Effect of Nucleoplasmin on a Nucleosome Structure
}

\author{
Akiko IIHARA, ${ }^{*}$ Koji SATO, ${ }^{*}$ Kentaro HozUmi, ${ }^{*}$ Masanori YAMADA,,$* * *$ \\ Hiroyuki YAMAMOTO, ${ }^{* *}$ Motoyoshi NOMIZU, ${ }^{*}$ and Norio NISHI**, ${ }^{*}$ \\ *Laboratory of Bio-Material Chemistry, Division of Bioscience, Graduate School of Environmental \\ Earth Science, Hokkaido University, Kita-ku, Sapporo 060-0810, Japan \\ ${ }^{* *}$ Faculty of Textile Science and Technology, Shinshu University, Ueda 386-8567, Japan
}

(Received October 17, 2001; Accepted January 16, 2002)

\begin{abstract}
Nucleoplasmin, isolated from the Xenopus laevis egg, was the first protein defined as a molecular chaperone. DNA forms a nucleosome structure with histones in eucaryotic somatic cells. Nucleoplasmin promotes the assembly of the nucleosome structure. We have now determined the effect of nucleoplasmin on the structure of the nuclease digested-nucleohistone (d-NH). The d-NH was prepared from nucleohistone by treatment with micrococcal nuclease. The DNA of the d-NH showed 200 bp ladder bands on an agarose gel electrophoresis. The Circular dichroism spectra of nucleohistone demonstrated an $\alpha$-helical structure with spectra minima at 208 and $222 \mathrm{~nm}$, while that of the $\mathrm{d}-\mathrm{NH}$ showed a minimum peak at $228 \mathrm{~nm}$. The turbidity of d-NH was found to be higher than that of nucleohistone, suggesting that $\mathrm{d}-\mathrm{NH}$ was aggregated. The aggregation was inhibited by an addition of $\mathrm{NaCl}$. Furthermore, guanidine $\mathrm{HCl}$ reduced the d-NH aggregation, while urea did not affect the aggregation. These results suggest that hydrogen bonds and/or ionic charges were mainly involved in the aggregation. When nucleoplasmin was added to a solution of d-NH, the mixtures possessed an $\alpha$-helical conformation. Poly-L-glutamic acid was also found to inhibit the aggregation and to promote the formation of $\alpha$-helical structures, however, this was not as effective as of nucleoplasmin. The conformational thermal stability of the nucleoplasmin/d-NH mixture was higher than that of $\mathrm{d}-\mathrm{NH}$ alone. These results indicate that nucleoplasmin inhibits aggregation of d-NH and increases the $\alpha$-helical structure of the core histones. Nucleoplasmin seems to play a critical role in the nucleosome assembly as a molecular chaperone by inhibiting the aggregation of histone and DNA. These data define the molecular mechanisms of the nucleosome assembly by nucleoplasmin.

KEY WORDS Nucleoplasmin / Nucleosome Structure / Molecular Chaperone / Nuclease

Digested-Nucleohistone / Alpha-Helical Structure / DNA / Nucleosome Assembly /
\end{abstract}

DNA is highly compacted into a chromatin structure in the eukaryotic chromosome. Chromatin consists of numerous nucleosomes in which DNA coils around the histone cores approximately every $200 \mathrm{bp} .{ }^{1}$ In the nucleosome, histone forms an octamer that consists of two units of histones H2A, H2B, H3, and H4. ${ }^{1-4}$ Histones are positively charged proteins which are thought to bind with DNA via their ionic interactions. ${ }^{5-7}$ Additionally, a hydrophobic interaction and hydrogen bonding were also suggested to be responsible for the DNAhistone binding. ${ }^{8}$ Histone molecules contain many positively charged amino acids in their $\mathrm{N}$ - and C-terminal regions, and there are many hydrophobic amino acids in their central region. This characteristic amino acid sequence of histones is thought to be important for stabilization of the $\alpha$-helical structure and for assembly of the core histone complex.

Nucleoplasmin, the first protein defined as a molecular chaperone, was isolated from Xenopus laevis eggs. It was found to promote nucleosome assembly by binding with histones H2A-H2B and transferring them to DNA. ${ }^{9-11}$ Nucleoplasmin is an acidic and phosphorylated protein, which forms a stable pentamer. ${ }^{10,11} \mathrm{Re}-$ cently, nucleoplasmin was found to promote sperm decondensation. ${ }^{12-15}$ Nucleoplasmin was also found to bind protamine, a sperm-specific basic nuclear protein, which could displace histones H2A and H2B. ${ }^{12-14,16,17}$ We have previously demonstrated the interactions of nucleoplasmin with protamine, histone, and nucleohistone. ${ }^{18,19}$ Nucleoplasmin contains an acidic domain consisting of approximately 20 glutamic acid residues. ${ }^{20,21}$ Poly-L-glutamic acid (PE) ${ }^{1}$ promotes nucleosome assembly in vitro. ${ }^{11}$ It is presumed that the acidic domain in the nucleoplasmin plays a critical role in the promotion of nucleosome assembly. However, the mechanisms of the nucleoplasmin-mediated nucleosome assembly are not well understood. In this report, we demonstrate the effect of nucleoplasmin on the structure of the nuclease digested-nucleohistone (d-NH), which involves mono-, di-, tri-, and oligonucleosomes. This d-NH is self-aggregated. We characterized the aggregation using circular dichroism (CD) spectroscopy and a UV spectrometer under various conditions. Using the d-NH, we evaluated the effect of the nucleoplasmin on nucleosome aggregation and on the $\alpha$-helical structure of the core histones. 


\section{EXPERIMENTAL}

\section{Purification of Nucleoplasmin}

Nucleoplasmin was purified from Xenopus laevis eggs as previously described. ${ }^{10,18,22}$ Briefly, chrionic gonadotoropin (Teikoku-zouki Pharmaceutical Co., Tokyo, Japan) was injected in frogs (500 units/frog), then after $13 \mathrm{~h}$, the mature eggs were obtained. The collected eggs were dejellied by a $2 \%$ cysteine solution ( $\mathrm{pH} \mathrm{8.2)} \mathrm{and} \mathrm{washed} \mathrm{with} 10 \mathrm{mM}$ Tris-HCl buffer $(\mathrm{pH} 7.4)$ in the presence of $100 \mathrm{mM} \mathrm{KCl}$ and $2 \mathrm{mM}$ $\mathrm{MgCl}_{2}$. The eggs were homogenized and centrifuged $(10 \mathrm{~min}, 10000 \times \mathrm{g})$, and the supernate was further centrifuged $(60 \mathrm{~min}, 150000 \times \mathrm{g})$. The crude protein was purified by ion exchange and gel filtration column chromatographies using DEAE-Sepharose CL-6B (Pharmacia LKB., Uppsala, Sweden) and Superdex 200 (Pharmacia LKB.), respectively. The purity was confirmed by SDS-PAGE, and the sperm nucleus decondensation activity was examined as previously reported. ${ }^{18}$

\section{Preparation of Digested-Nucleohistone (d-NH)}

Calf thymus nucleohistone (Sigma Chemical Co., St. Louis, USA) was dissolved in $10 \mathrm{mM}$ Tris- $\mathrm{HCl}(\mathrm{pH}$ 7.4) at a $0.5 \mu \mathrm{M}$ histone concentration (abs. 0.6 at $280 \mathrm{~nm}$ and abs. 1.0 at $260 \mathrm{~nm}$ ). Micrococcal nuclease (MNase, $4 \mu \mathrm{L}$ of 100 units $\mathrm{mL}$, Sigma Chemical Co.) was added to $400 \mu \mathrm{L}$ of the nucleohistone solution and incubated at $20^{\circ} \mathrm{C}$. All experiments were carried out using the solution within $10 \mathrm{~min}$ after the enzyme digestion.

\section{Agarose Gel Electrophoresis Analysis}

Nucleohistone was digested with MNase as described above. Aliquots $(400 \mu \mathrm{L})$ were taken at various time intervals $(0,20,60$, and $180 \mathrm{~min})$ and the nuclease activity was terminated by the addition of $10 \mathrm{mM}$ EDTA. All samples were treated with trypsin (Wako Pure Chemical Industried, Ltd., Osaka, Japan) at a final trypsin concentration of $1 \mathrm{mg} \mathrm{mL}^{-1}$ at $37^{\circ} \mathrm{C}$ for $20 \mathrm{~h}$. The DNA was then extracted with phenol-chloroform $(400 \mu \mathrm{L})$ and precipitated with ethanol $(400 \mu \mathrm{L})$. The extraction and precipitation procedures were repeated three times. The extracted DNA was analyzed by $2 \%$ agarose gel electrophoresis. The DNA was detected on agarose gels by staining with ethidium bromide under UV illumination.

\section{Circular Dichroism (CD) Analysis}

All sample solutions were prepared at a final histone concentration of $0.5 \mu \mathrm{M}$ in $10 \mathrm{mM}$ Tris- $\mathrm{HCl}$ (pH 7.4). The CD spectra were recorded at various wavelengths on a Jasco Model J-720 CD spectropolarimeter (Japan Spectroscopic Co., Tokyo, Japan) with a $1 \mathrm{~mm}$ path length at $20^{\circ} \mathrm{C}$.

\section{Turbidity Measurements}

All sample solutions were prepared as described above. The turbidities were determined by UV scattering from 350 to $250 \mathrm{~nm}$ at various temperatures on a CARY 5E UV-Vis-NIR spectrophotometer (Varian Australia Pty., Ltd., Australia). The turbidities of the protein-DNA complexes were determined from the absorbance at $320 \mathrm{~nm}$, which is a non-absorption wavelength for nucleohistone ${ }^{23}$

\section{Thermal Stabilities of $d-\mathrm{NH}$}

The d-NH solution at the final histone concentration of $0.5 \mu \mathrm{M}$ in $10 \mathrm{mM}$ Tris- $\mathrm{HCl}$ ( $\mathrm{pH} 7.4$ ) was prepared as described above with a $20 \mathrm{~min}$ MNase treatment. The CD spectra from 250 to $200 \mathrm{~nm}$ and UV spectra from 350 to $250 \mathrm{~nm}$ were measured at different temperatures. The temperature was gradually elevated from 20 to $80^{\circ} \mathrm{C}$ in $5^{\circ} \mathrm{C}$ steps.

\section{pH Effect on Conformation of $d-N H$}

The d-NH solution in $10 \mathrm{mM}$ Tris- $\mathrm{HCl}(\mathrm{pH} 7.4)$ was adjusted to $\mathrm{pH} 2-10$ using $\mathrm{HCl}$ with a final histone concentration of $0.5 \mu \mathrm{M}$. The $\mathrm{CD}$ spectra were recorded from 250 to $200 \mathrm{~nm}$ at $20^{\circ} \mathrm{C}$ as described above. The turbidities of the d-NH solutions ( $\mathrm{pH} 2-10)$ were also determined by UV scattering from 350 to $250 \mathrm{~nm}$ as described above.

\section{Salt Effect on Conformation of d-NH}

The d-NH solution $(200 \mu \mathrm{L}$, histone concentration $=$ $1 \mu \mathrm{M})$ was diluted with $200 \mu \mathrm{L}$ of the same buffer containing $0-4 \mathrm{M} \mathrm{NaCl}$. The $\mathrm{CD}$ spectra were recorded from 250 to $200 \mathrm{~nm}$ at $20^{\circ} \mathrm{C}$ as described above. The turbidities of the d-NH solutions in the presence of various concentrations of $\mathrm{NaCl}$ were measured from 350 to $250 \mathrm{~nm}$ as described above. The CD spectra of the d-NH in PBS were also measured at different temperatures. The temperature was gradually elevated as described above.

\section{Guanidine Hydrochloride and Urea Denaturation of $d$ - NH}

The d-NH solution (final conc. of histone $=4.0 \mu \mathrm{M}$ ) in $10 \mathrm{mM}$ Tris- $\mathrm{HCl}(\mathrm{pH}$ 7.4) was diluted with the same buffer containing various concentrations of ei- 
(a)

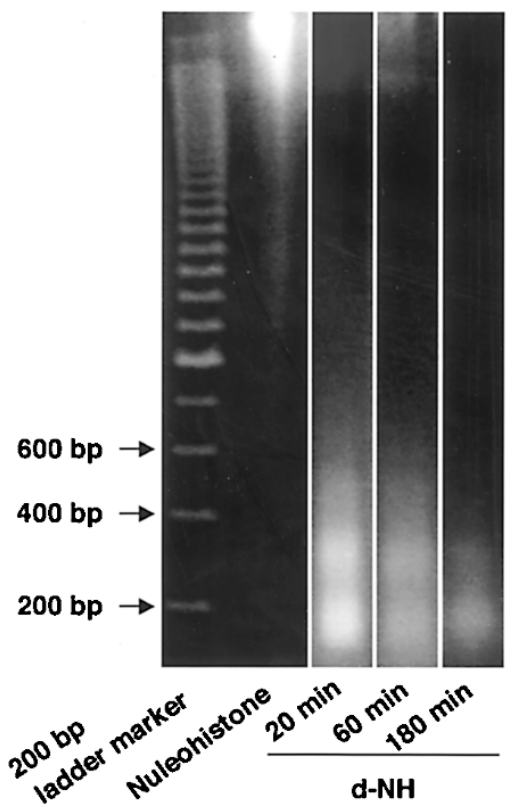

(b)

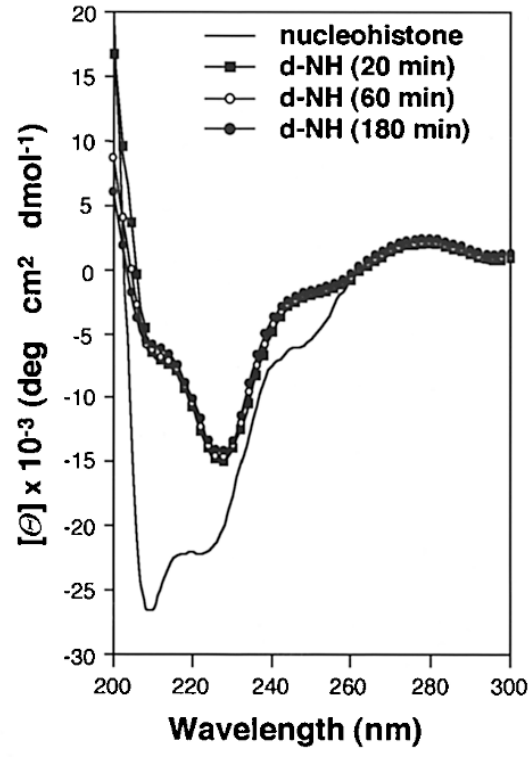

(c)

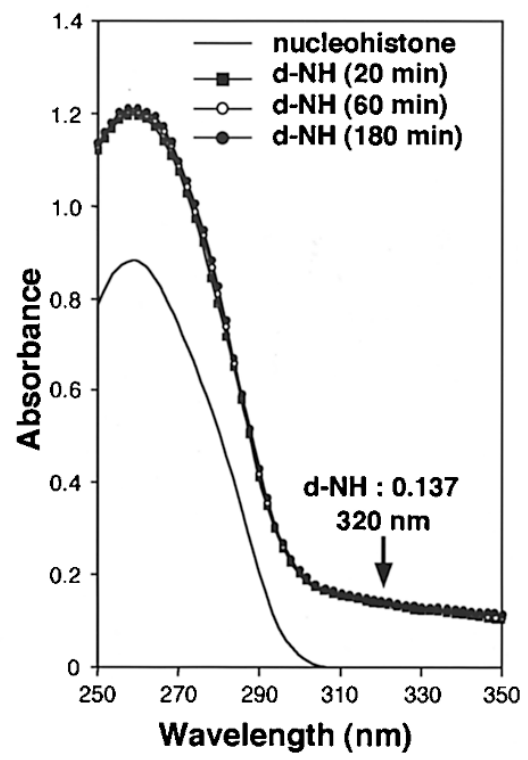

Figure 1. Agarose gel electrophoresis (a), CD spectra (b), and turbidities (c) of nuclease digested-nucleohistone (d-NH). (a) Nucleohistone $(0.5 \mu \mathrm{M})$ was treated with micrococcal nuclease (MNase) $\left(0.5\right.$ units $\left.\mathrm{mL}^{-1}\right)$ at $20^{\circ} \mathrm{C}$ for 20,60 , and 180 min. DNA was extracted and analyzed by $2 \%$ agarose gel electrophoresis. (b) Nucleohistone (histone octamer $=0.5 \mu \mathrm{M}$ ) was treated with $\mathrm{MNase}\left(0.5 \mathrm{units} \mathrm{mL}^{-1}\right)$ at $20^{\circ} \mathrm{C}$. Aliquots were collected at 20,60, and $180 \mathrm{~min}$ and the $\mathrm{CD}$ spectra were recorded from 300 to $200 \mathrm{~nm}$ in $10 \mathrm{mM} \mathrm{Tris-HCl}(\mathrm{pH} 7.4$ ) at $20^{\circ} \mathrm{C}$. (c) Nucleohistone (histone octamer $=0.5 \mu \mathrm{M}$ ) was treated with MNase $\left(0.5\right.$ units $\left.\mathrm{mL}^{-1}\right)$ at $20^{\circ} \mathrm{C}$. Aliquots were collected at 20,60 , and $180 \mathrm{~min}$ and the turbidities were determined by UV scattering from 350 to $250 \mathrm{~nm}$.

ther guanidine hydrochloride or urea. The CD spectra of the d-NH were measured from 240 to $220 \mathrm{~nm}$ at $20^{\circ} \mathrm{C}$ as described above. The turbidities of the $\mathrm{d}-$ $\mathrm{NH}$ in the presence of various concentrations of either guanidine hydrochloride or urea were also determined as described above.

\section{Mixing Experiments}

Nucleoplasmin $\left(M_{\mathrm{w}}: 22000\right.$, nucleoplasmin pentamer: nucleohistone $=1: 1)$, poly-L-glutamic acid $(\mathrm{PE}$, $M_{\mathrm{w}} ;>8000$, concentration adjusted to all the acidic amino acid residues of the nucleoplasmin) and polyL-lysine $\left(\mathrm{PK}, M_{\mathrm{w}} ;>8000\right.$, concentration adjusted to the all basic amino acid residues of the nucleoplasmin) were added to the d-NH (final histone concentration = $0.5 \mu \mathrm{M})$. Bovine serum albumin (BSA) $(0.5 \mu \mathrm{M})$ was also added to the d-NH solution as a control. After the mixtures were incubated at $20^{\circ} \mathrm{C}$ for $5 \mathrm{~h}$, The $\mathrm{CD}$ spectra were measured from 250 to $200 \mathrm{~nm}$ at $20^{\circ} \mathrm{C}$. Turbidities of the nucleoplasmin/d-NH and PE/d-NH mixtures were also determined as described above.

\section{Time Course Analysis}

The nucleoplasmin/d-NH and PE/d-NH solutions, which were used above, were mixed at $20^{\circ} \mathrm{C}$. The $\mathrm{CD}$ spectra of the mixtures were recorded from 250 to $200 \mathrm{~nm}$ at various time points $(1-5 \mathrm{~h})$. The turbidity of the mixtures at various time points $(0-120 \mathrm{~min})$ were determined by UV time scattering at $320 \mathrm{~nm}$.

\section{Determination of Thermal Stabilities}

Sample solutions (at histone concentration of $0.5 \mu \mathrm{M})$ were prepared as described above. The CD spectra from 250 to $200 \mathrm{~nm}$ were measured at different temperatures. The temperature was gradually elevated from 20 to $80^{\circ} \mathrm{C}$ in $5^{\circ} \mathrm{C}$ steps. The thermal melting curves of the mixtures were determined from the mean residue ellipticities of the peak minima at $222 \mathrm{~nm}$ (nucleohistone, nucleoplasmin/d-NH, and $\mathrm{PE} / \mathrm{d}-\mathrm{NH}$ ) and $228 \mathrm{~nm}(\mathrm{~d}-\mathrm{NH})$.

\section{RESULTS}

\section{Preparation and Conformation of Digested- nucleohistone (d-NH)}

Nucleohistone was treated with micrococcal nuclease (MNase) and aliquots at various intervals (20, 60 , and $180 \mathrm{~min}$ ) were obtained. When the DNA of the digested-nucleohistone (d-NH) was analyzed by agarose gel electrophoresis, the MNase treated samples showed 200 bp ladder bands (Figure 1a). These results indicated that the linker DNA of the nucleohistone was degradated by the MNase treatments, and mono-, di-, tri-, and oligo-nucleosomes were produced. The con- 
(a)

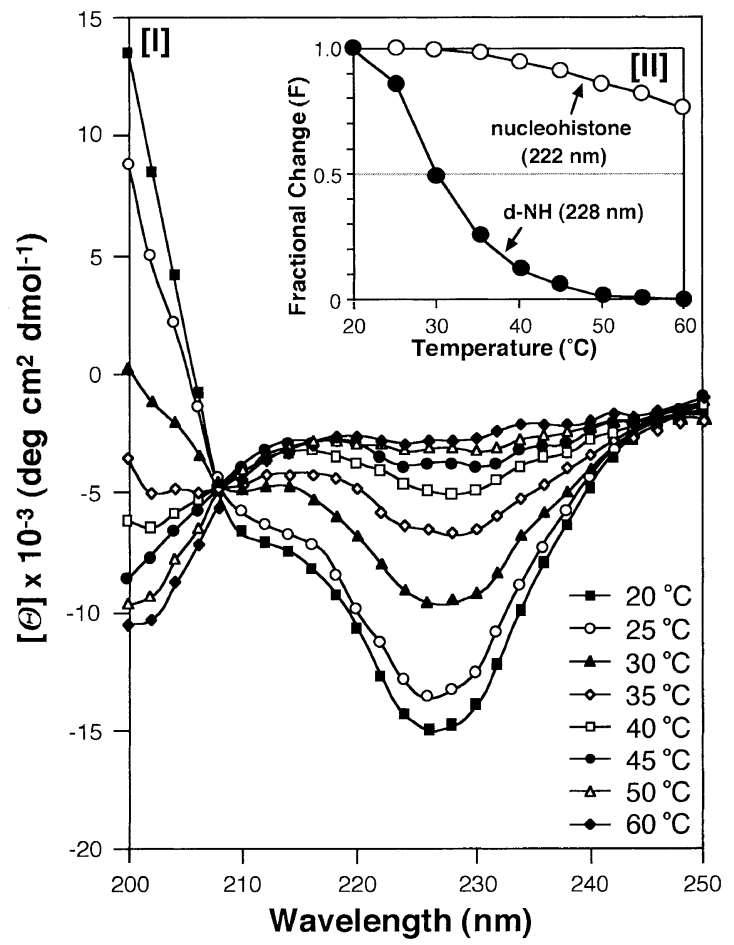

(b)

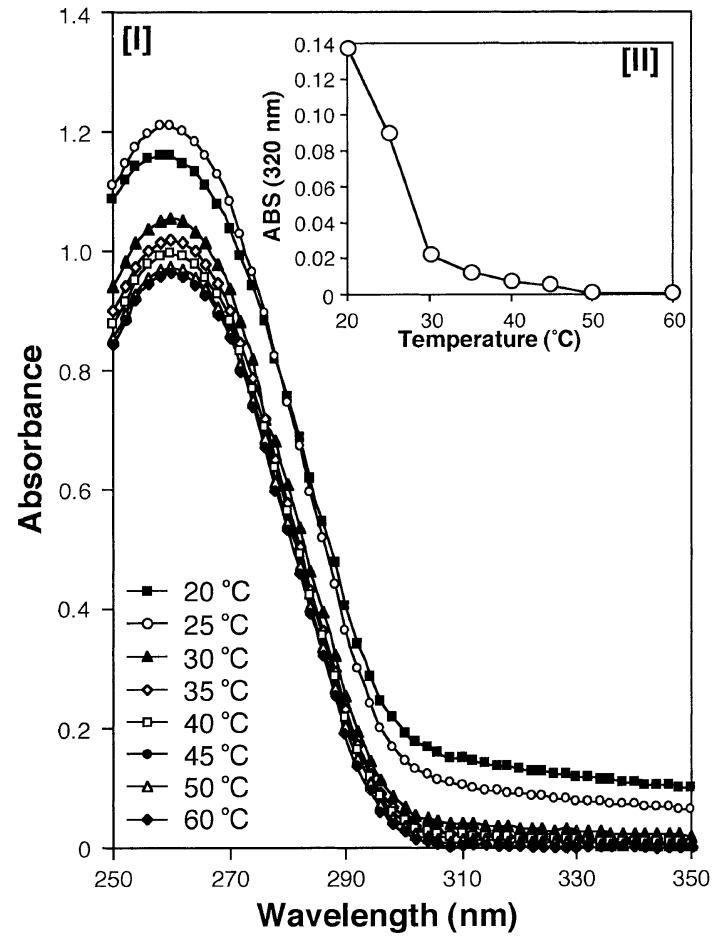

Figure 2. CD spectra (a) and turbidities (b) of the d-NH at different temperatures. The d-NH solution (histone octamer $=0.5 \mu \mathrm{M}$ ) with a 20 min MNase treatment was used. (a-I) The CD spectra were recorded from 200 to $250 \mathrm{~nm}$ in $10 \mathrm{mM} \mathrm{Tris}-\mathrm{HCl}(\mathrm{pH} 7.4$ ) solution at 20-80 $\mathrm{C}$. (a-II) Fractional change in d-NH $(228 \mathrm{~nm})$ at different temperatures was plotted. The CD spectra of nucleohistone were also measured at different temperatures at $20-80^{\circ} \mathrm{C}$ (data not shown), and the fractional change at $222 \mathrm{~nm}$ was plotted. (b-I) The turbidities were determined by UV scattering from $350 \mathrm{~nm}$ to $250 \mathrm{~nm}$ in $10 \mathrm{mM}$ Tris- $\mathrm{HCl}$ (pH 7.4) from $20-80^{\circ} \mathrm{C}$. (b-II) The absorbance at $320 \mathrm{~nm}$, which indicates turbidity of the solutions, was plotted at different temperatures.

formations of the nucleohistone and d-NH were evaluated by circular dichroism (CD) spectroscopy (Figure $1 \mathrm{~b}$ ). $\mathrm{CD}$ spectrum of nucleohistone showed peak minima at 208 and $222 \mathrm{~nm}$, suggesting that the core histones possessed an $\alpha$-helical structure (Figure 1b). $\mathrm{CD}$ spectra of the d-NH samples showed peak minimum at approx. $228 \mathrm{~nm}$ (Figure 1b). CD spectra of both samples showed a peak maximum at around $275 \mathrm{~nm}$, suggesting that the d-NH samples contained double stranded DNA. Next, the absorbance of the sample solutions was measured from 350 to $250 \mathrm{~nm}$ to analyze the turbidities (Figure 1c). The turbidities (reflected by the absorbance at $320 \mathrm{~nm}$ ) of the MNasetreated samples (20-180 min) were comparable, and were higher than that of nucleohistone. These results indicated that the core histones, which possessed an $\alpha$ helical conformation in the nucleosome, were aggregated by the nuclease digestion. All the d-NH samples, which were treated with the nuclease for 20,60, and $180 \mathrm{~min}$, showed similar DNA degradation and aggregation. A 20 min nuclease digested-nucleohistone sample was used for all the additional experiments.

\section{Thermal Stability of $d-N H$}

Thermal transitions of conformation and turbidity of the d-NH were determined by monitoring the changes in the CD spectra (Figure 2a) and UV scattering (Figure $2 b$ ) at various temperatures. The $C D$ spectra changed with temperature and an isosbestic point at $207 \mathrm{~nm}$ was defined (Figure 2a). The CD ellipticity signal at $228 \mathrm{~nm}$ increased when the temperature was gradually increased (Figure 2a). These results indicated that the histones in $\mathrm{d}-\mathrm{NH}$ formed a specific structure, which was different from that of the core histone in the nucleosome. The d-NH turbidity decreased when the temperature was gradually increased (Figure $2 b$ ). The $\mathrm{UV}$ absorbance at $320 \mathrm{~nm}$ completely disappeared at $35^{\circ} \mathrm{C}$ (Figure $2 \mathrm{~b}$ ). Thus, the aggregation of $\mathrm{d}-\mathrm{NH}$ was eliminated at temperatures higher than $35^{\circ} \mathrm{C}$. In addition, the thermal transitions of the d-NH conformation and turbidity were not reversible. These results suggested that the low $\alpha$-helix of d-NH in the CD spectra was caused not by the high turbidity but by the conformational change in the histones. 
(a)

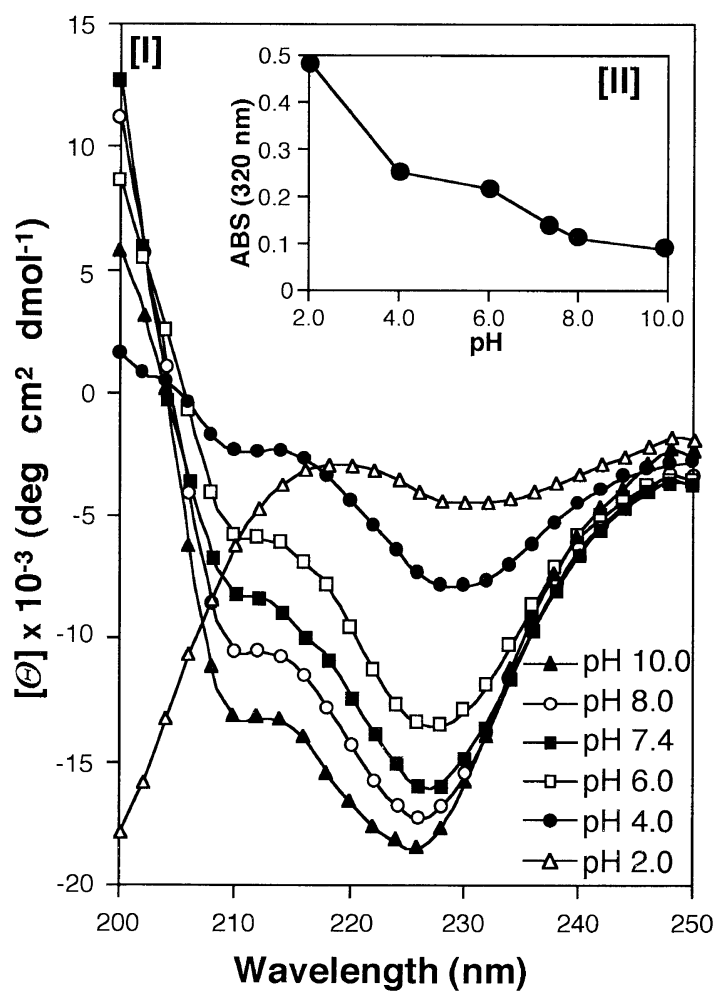

(b)

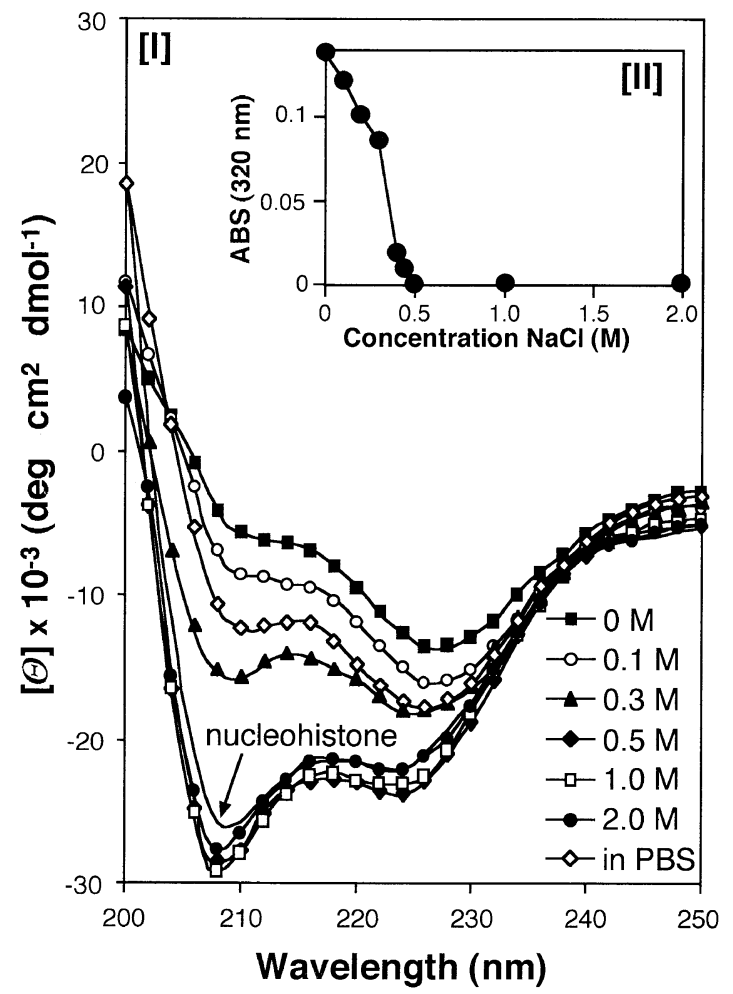

Figure 3. $\mathrm{pH}(\mathrm{a})$ and salt (b) effects on the conformation of d-NH. The d-NH solution (histone octamer $=0.5 \mu \mathrm{M}$ ) with a 20 min $\mathrm{MNase}$ treatment was used. (a-I) The CD spectra of the d-NH were recorded from 250 to $200 \mathrm{~nm}$ in $10 \mathrm{mM}$ Tris- $\mathrm{HCl}$ solutions under different $\mathrm{pH}$ conditions at $20^{\circ} \mathrm{C}$. (a-II) The turbidities were determined by UV scattering from 350 to $250 \mathrm{~nm}$ in $10 \mathrm{mM}$ Tris- $\mathrm{HCl}$ solutions under different $\mathrm{pH}$ conditions. Absorbance at $320 \mathrm{~nm}$ (= turbidity) were plotted under different $\mathrm{pH}$ conditions. (b-I) The CD spectra of the d-NH solutions were recorded from 250 to $200 \mathrm{~nm}$ at $20^{\circ} \mathrm{C}$ in $10 \mathrm{mM}$ Tris- $\mathrm{HCl}$ (pH 7.4) containing various concentrations of $\mathrm{NaCl}$ or in PBS. (b-II) The turbidities were determined by UV scattering from 350 to $250 \mathrm{~nm}$ in $10 \mathrm{mM}$ Tris- $\mathrm{HCl}$ (pH 7.4) containing various concentrations of $\mathrm{NaCl}$ or in PBS. The absorbance at $320 \mathrm{~nm}$ (= turbidity) was plotted at various concentrations of $\mathrm{NaCl}$.

\section{pH Dependence on Conformation of d-NH}

The $\mathrm{pH}$ effects on the conformation of d-NH using CD spectroscopy (Figure 3a-I) and on the turbidity (Figure $3 \mathrm{a}-\mathrm{II})$ were examined at $20^{\circ} \mathrm{C}$. When the $\mathrm{CD}$ spectra were examined under basic conditions, the negative ellipticity at $228 \mathrm{~nm}$ was slightly increased. At low $\mathrm{pH}$, however, the negative ellipticity was significantly decreased, and d-NH showed a random coil structure at $\mathrm{pH} 2.0$ (Figure 3a-I). The turbidity of d$\mathrm{NH}$ increased under acidic conditions and slightly decreased at higher $\mathrm{pH}$ (Figure 3a-II). In addition, the $\mathrm{pH}$ effects on the conformation of d-NH were not reversible. These results suggested that intra- and/or intermolecular ionic interactions were involved in the aggregation. Other interactions, such as hydrophobic and hydrogen bond interactions, could also be involved in the aggregation.

\section{Salt Effects on Conformation of d-NH}

The CD spectra and turbidities of d-NH were determined in the presence of various concentrations of $\mathrm{NaCl}$ (Figure 3b-I, II). When the $\mathrm{NaCl}$ concentrations increased $(0-1 \mathrm{M})$, the $\alpha$-helical content of the d-NH was increased (Figure 3b-I). Additional $\mathrm{NaCl}(1-2 \mathrm{M})$ did not further increase the $\alpha$-helical content of d-NH (Figure 3b-I). The d-NH in the presence of $1 \mathrm{M} \mathrm{NaCl}$ showed a similar CD spectrum to that of nucleohistone. The turbidity of d-NH decreased as the $\mathrm{NaCl}$ concentration increased. The turbidity was almost eliminated when the $\mathrm{NaCl}$ concentration was $0.5 \mathrm{M}$ (Figure 3b-II). The increased $\alpha$-helical structure in the presence of a high salt concentration can be explained by several possible mechanisms. ${ }^{24,25}$ Salts can bind to charged amino acid residues and inhibit non-specific ionic interactions involved in the d-NH aggregation. The d-NH may increase in $\alpha$-helicity due to the blocking of non-specific ionic interactions by the high salt. These results suggested that ionic interactions were mainly involved in the conformation of d-NH. In the presence of $1 \mathrm{M} \mathrm{NaCl}$, $\mathrm{d}-\mathrm{NH}$ was found to be more stable than that in the absence of $\mathrm{NaCl}$ (data not shown). Highly concentrated salts inhibited the d-NH aggregation and stabilized the $\alpha$-helical conformation. In PBS $(0.15 \mathrm{M} \mathrm{NaCl})$, the CD spectrum of d-NH was intermediate between that of d$\mathrm{NH}$ in $0.1 \mathrm{M}$ and $0.3 \mathrm{M} \mathrm{NaCl}$. This result suggested that the d-NH aggregates and its histones do not possess an 
(b)
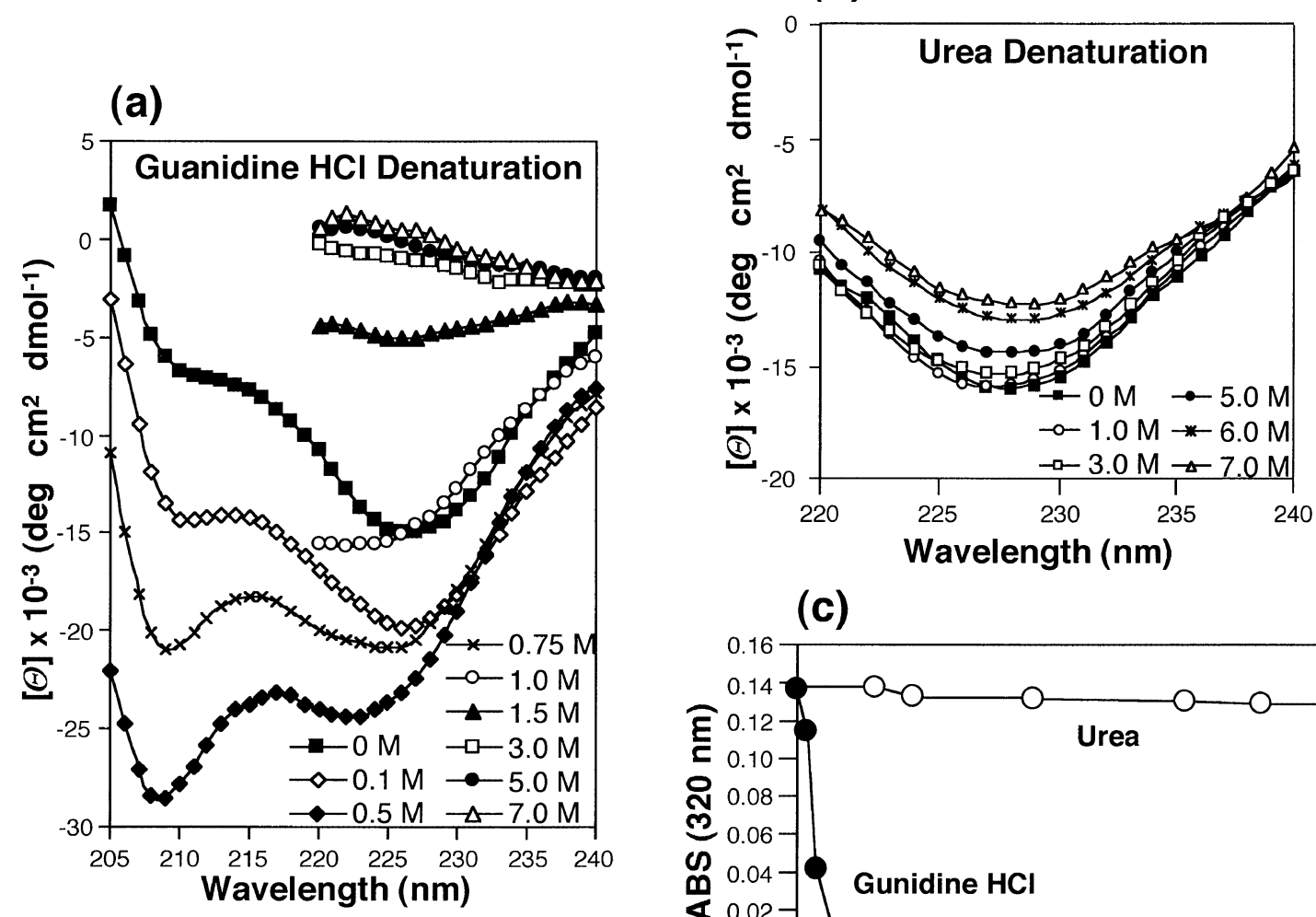

(c)

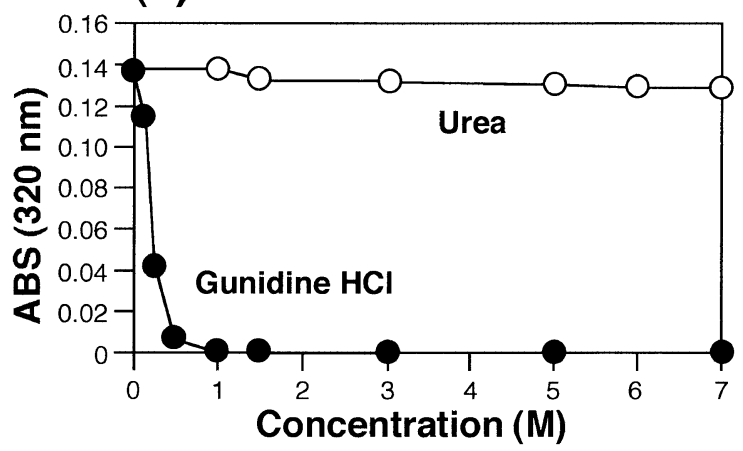

Figure 4. Effect of guanidine hydrochloride (a) and urea (b) denaturation on the conformation of d-NH. (a) The CD spectra of the d-NH were recorded from 240 to 205 or $220 \mathrm{~nm}$ in $10 \mathrm{mM}$ Tris- $\mathrm{HCl}$ (pH 7.4) containing various concentrations of guanidine hydrochloride. (b) The CD spectra of d-NH were recorded from 240 to $220 \mathrm{~nm}$ in $10 \mathrm{mM}$ Tris- $\mathrm{HCl}$ (pH 7.4) containing various concentrations of urea. (c) The turbidities of the d-NH solutions were determined by UV scattering from 350 to $250 \mathrm{~nm}$ in $10 \mathrm{mM}$ Tris- $\mathrm{HCl}$ (pH 7.4) containing various concentrations of guanidine hydrochloride or urea. The absorbance at $320 \mathrm{~nm}$ (= turbidity) was plotted at various concentrations of guanidine hydrochloride or urea.

$\alpha$-helical structure under physiological ionic strength conditions.

\section{Urea and Guanidine Hydrochloride Denaturation}

The conformational stability of d-NH was determined by monitoring the changes in the $\mathrm{CD}$ spectra $(228 \mathrm{~nm})$ at various concentrations of urea and guanidine hydrochloride (Figure 4). As shown in Figure 4a, the $\alpha$-helicity of d-NH increased at low guanidine hydrochloride concentrations $(0-0.5 \mathrm{M})$. The $\mathrm{CD}$ signal intensity of d-NH decreased when the guanidine hydrochloride concentration was increased from 0.5 to $7 \mathrm{M}$. When the guanidine hydrochloride concentration exceeded $3 \mathrm{M}$, the d-NH possessed a random coil structure. The CD spectra of d-NH were not significantly affected when the urea concentration was increased from 0-7 M (Figure 4b).

The turbidity of d-NH in the presence of various concentrations of either guanidine hydrochloride or urea was determined by UV scattering (Figure 4c). The turbidity of d-NH decreased as the concentration of guani- dine hydrochloride increased and it disappeared at approximately $0.5 \mathrm{M}$. When urea was added to the solution, the turbidity did not change. These results suggested that the aggregation of d-NH mainly occurred due to ionic interactions and/or hydrogen bonds, but not hydrophobic interactions.

Effects of Nucleoplasmin, PE, and PK on the Conformation and Aggregation of $d-\mathrm{NH}$

We examined the effects of nucleoplasmin, poly-Lglutamic acid (PE), and poly-L-lysine (PK) on the conformation of d-NH using CD spectroscopy (Figure 5a) (Table I). When nucleoplasmin was added to the solution of d-NH, the mixture showed a CD spectrum with peak minima at 208 and $222 \mathrm{~nm}$ (Figure 5a) and the $\alpha$ helicity also increased (59\% helix) (Table I). When PE was added to the d-NH solution, the $\alpha$-helicity was increased. The $\alpha$-helicity of PE/d-NH (50\%) was lower than that of nucleoplasmin/d-NH (59\%). However, when PK was added to the d-NH solution, the structure of d-NH was lost. The addition of bovine serum 
(a)

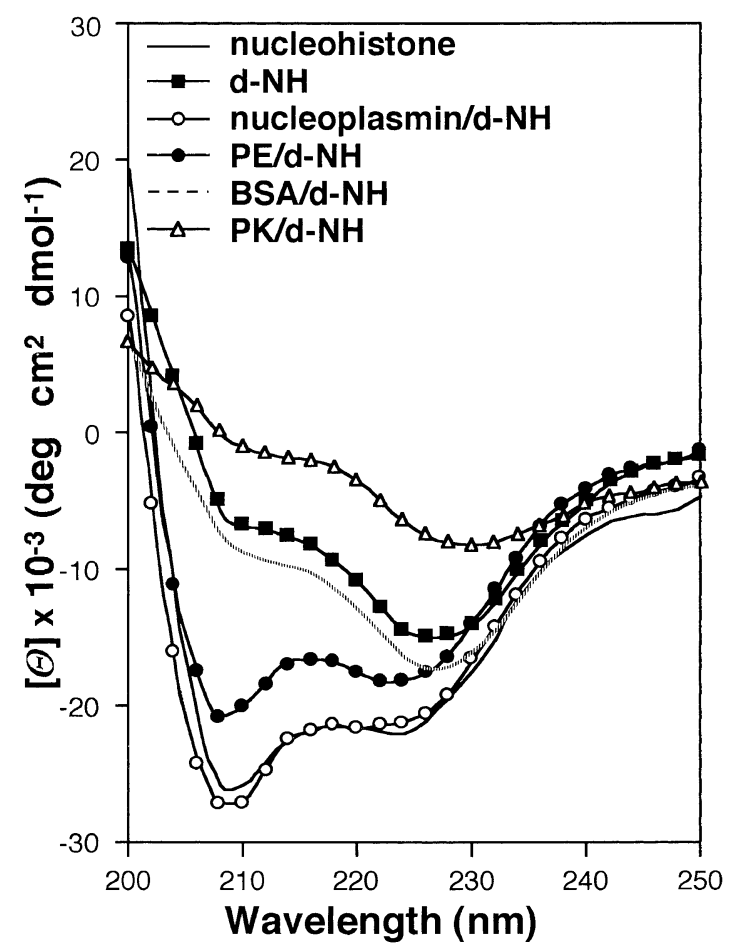

(b)

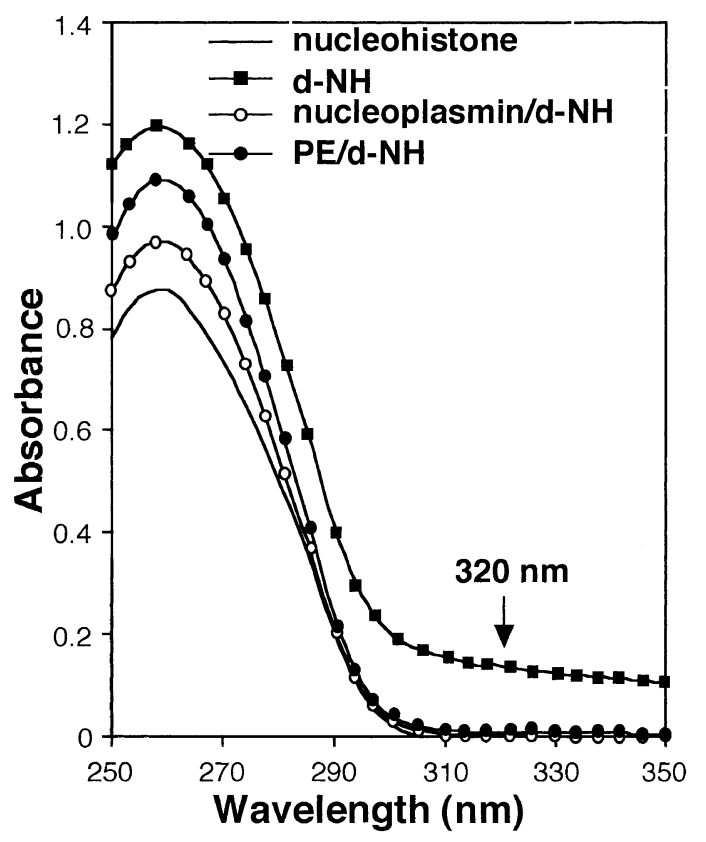

Figure 5. Effect of nucleoplasmin and PE on the conformation (a) and aggregation (b) of the d-NH. (a) The CD spectra of nucleoplasmin/d-NH, PE/d-NH, and PK/d-NH mixtures were recorded from 250 to $200 \mathrm{~nm}$ at $20^{\circ} \mathrm{C}$ in $10 \mathrm{mM} \mathrm{Tris-HCl}$ (pH 7.4). (nucleohistone: nucleoplasmin $=1: 1$, nucleohistone: $\mathrm{PE}=1: 1$. nucleohistone: $\mathrm{PK}=1: 1)$ - and --- indicate the spectra of nucleohistone and $\mathrm{BSA} / \mathrm{d}-\mathrm{NH}$ for control, respectively. (b) The turbidities of nucleoplasmin/d-NH, and PE/d-NH were determined by UV scattering from 350 to $250 \mathrm{~nm}$ at $20^{\circ} \mathrm{C}$ in $10 \mathrm{mM}$ Tris- $\mathrm{HCl}(\mathrm{pH} 7.4)$. Absorbance at $320 \mathrm{~nm}$ (= turbidity) of nucleohistone, d-NH, nucleoplasmin/d-NH mixture, and $\mathrm{PE} / \mathrm{d}-\mathrm{NH}$ mixture were $0.000,0.137,0.002$, and 0.007 , respectively.

Table I. Conformation and thermal stability of nucleohistone, d-NH, nucleoplasmin/d-NH, and PE/d-NH mixtures

\begin{tabular}{lcc}
\hline Samples $^{\mathrm{a}}$ & $\mathrm{fH}^{\mathrm{b}}$ & $T_{\mathrm{m}}(\mathrm{PC})^{\mathrm{c}}$ \\
\hline Nucleohistone & 60 & 76 \\
d-NH & 35 & 31 \\
d-NH(in PBS) & 44 & 35 \\
Nucleoplasmin/d-NH & 59 & 47 \\
PE/d-NH & 50 & 52 \\
\hline
\end{tabular}

${ }^{a}$ Each sample was prepared and their conformation and thermal stabilities were determined as described in Materials and Methods. All samples (histone octamer $=0.5 \mu \mathrm{M}$ ) were in 10 $\mathrm{mM}$ Tris-HCl (pH 7.4), except for d-NH in PBS. ${ }^{\mathrm{b}}$ The $\alpha$-helical content (fH) of each sample was calculated according to the assumption $^{39}$ of a $100 \% \alpha$-helix and $X$ number of amino acids in histones for each samples. The mean residue ellipticity $[\theta]$ at $222 \mathrm{~nm}$ is $[\theta]_{222}=-36300(1-2.57 / X) .{ }^{\mathrm{c}} T_{\mathrm{m}}$ value was obtained from the thermal transitional curve of each sample (Figure 7).

albumin (BSA) did not affect the conformation of d$\mathrm{NH}$. These results indicate that nucleoplasmin and PE interacted with d-NH and increased the $\alpha$-helicity of the nucleosome core histones. Furthermore, the turbidities of nucleoplasmin/d-NH and PE/d-NH were lower than that of d-NH (Figure 5b), while the addition of PK and BSA did not affect the turbidity of d-NH.
Next, we examined the time courses of the aggregation and turbidity of mixtures of d-NH and either nucleoplasmin or PE (Figure 6a, 6b). The nucleoplasmin/d$\mathrm{NH}$ mixture reached the peak maxima at 208 and $222 \mathrm{~nm}$ within $1 \mathrm{~h}$ (Figure 6a), while the turbidity almost disappeared within 10 min (Figure 6b). The PE/d$\mathrm{NH}$ mixture took more than $1 \mathrm{~h}$ to reach the peak maxima (Figure 6a), and the decrease in the turbidity was smaller than that of the nucleoplasmin/d-NH mixture (Figure 6b). Nucleoplasmin was found to interact with $\mathrm{d}-\mathrm{NH}$ and inhibit the aggregation more effectively compared to that of PE.

Thermal Stability of Nucleohistone, $d-N H$, Nucleoplasmin/d-NH, and PE/d-NH

The thermal stabilities of nucleohistone, d-NH, d$\mathrm{NH}$ (in PBS), nucleoplasmin/d-NH, and PE/d-NH were determined by monitoring changes in the $\mathrm{CD}$ spectra at various temperatures. The denaturation temperature $\left(T_{\mathrm{m}}\right)$ of d-NH was $31^{\circ} \mathrm{C}$ (at $228 \mathrm{~nm}$ ), while that of nucleohistone was $76^{\circ} \mathrm{C}$ (at $222 \mathrm{~nm}$ ) (Figure 7). The structures of nucleoplasmin/d-NH and PE/d-NH were found to be more stable than that of d-NH. The $T_{\mathrm{m}}$ value of the nucleoplasmin/d-NH mixture was $47^{\circ} \mathrm{C}$ (at $222 \mathrm{~nm}$ ), 
(a)

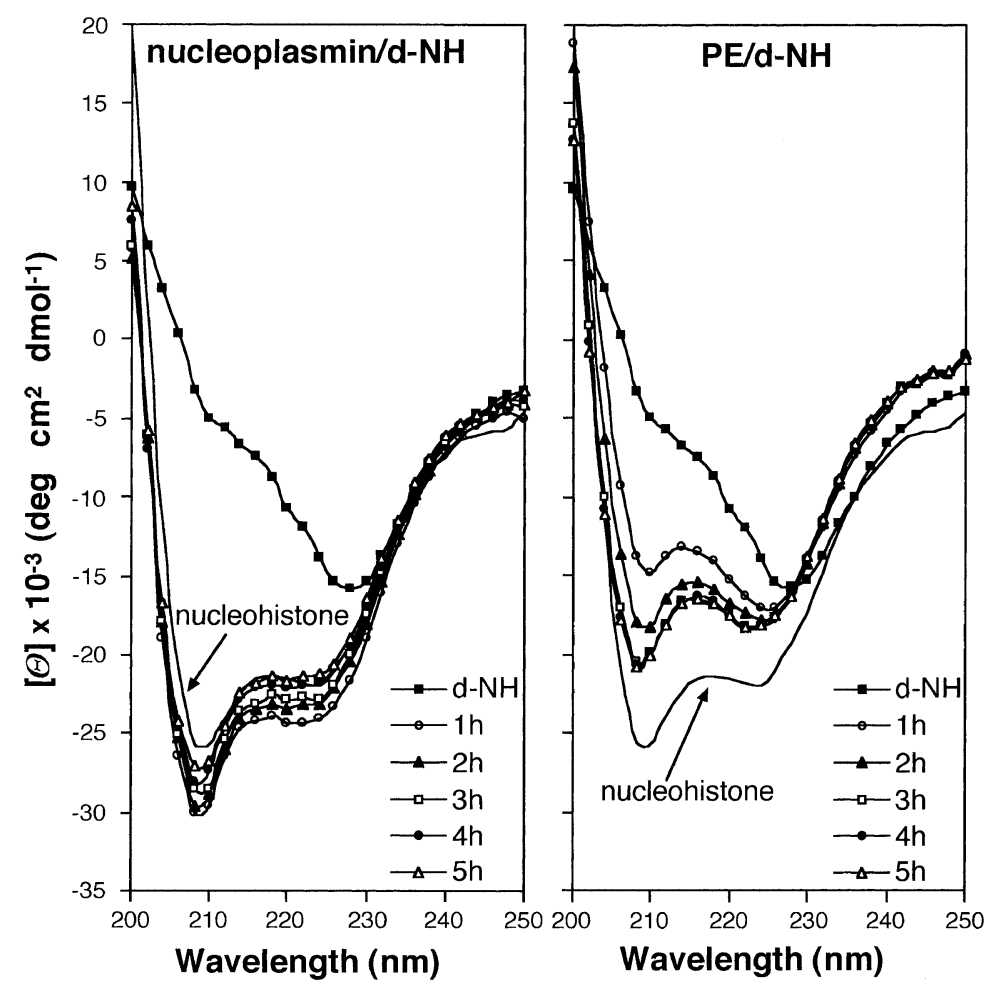

(b)

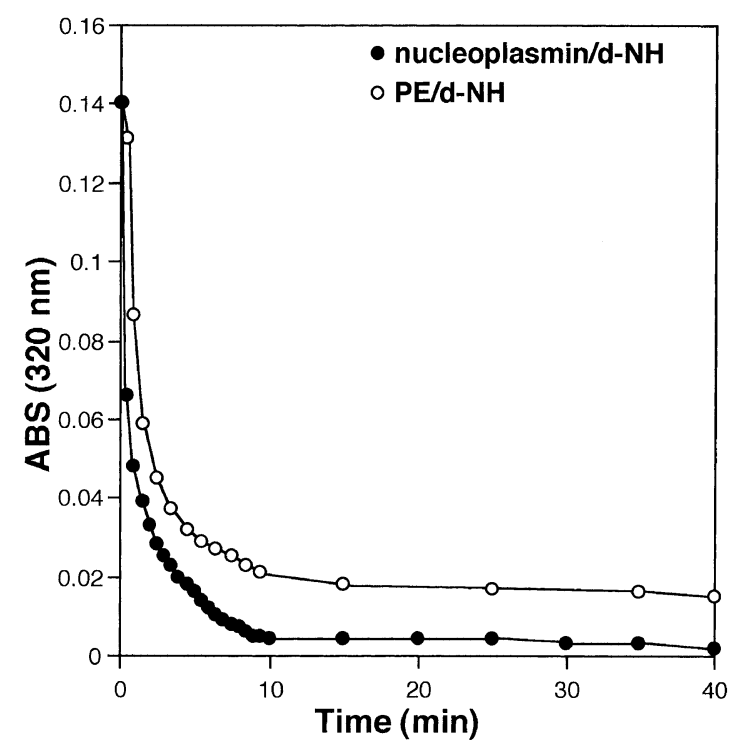

Figure 6. $\mathrm{CD}$ spectral and turbidity change of nucleoplasmin/d-NH and PE/d-NH mixtures at various times. (a) The CD spectra of nucleoplasmin/d-NH (I) and PE/d-NH (II) mixtures were recorded from 250 to $200 \mathrm{~nm}$ at $20^{\circ} \mathrm{C}$ in $10 \mathrm{mM}$ Tris- $\mathrm{HCl}$ (pH 7.4 ) at various mixing times $(1-5 \mathrm{~h})$. (b) Turbidities at various times $(0-40 \mathrm{~min})$ of the mixtures were determined by a UV time scattering at $320 \mathrm{~nm}$.

and that of the $\mathrm{PE} / \mathrm{d}-\mathrm{NH}$ mixture was $52^{\circ} \mathrm{C}$ (at $222 \mathrm{~nm}$ ) (Figure 7). These results suggested that nucleoplasmin and PE stabilized the conformation of d-NH.

\section{DISCUSSION}

Various models for the organization of nucleosomes in the super structure of chromatin have been studied. $^{26-28}$ However, it is not clear how the nucleosome chains are folded or coiled in the chromosome. Recently, a nucleosome structure was studied and our understanding of the chromatin structure has increased. ${ }^{29-32}$ The acidic proteins N1/N2 and nucleoplasmin were found to play a critical role in the nucleosome assembly. ${ }^{33}$ There are many limitations in the study of mechanisms involving the nucleosome assembly from DNA and histones by nucleoplasmin in vivo, since many other factors, such as $\mathrm{N} 1 / \mathrm{N} 2$ and highmobility group proteins (HMG), are involved in the process. When DNA and histones are mixed under physiological ionic strength conditions, they aggregate and form a disordered structure by non-specific ionic interactions. However, DNA in the presence of histones and nucleoplasmin was found to coil around the histones and form a nucleosome structure in vitro. We also showed nucleoplasmin bound to protamine and affected

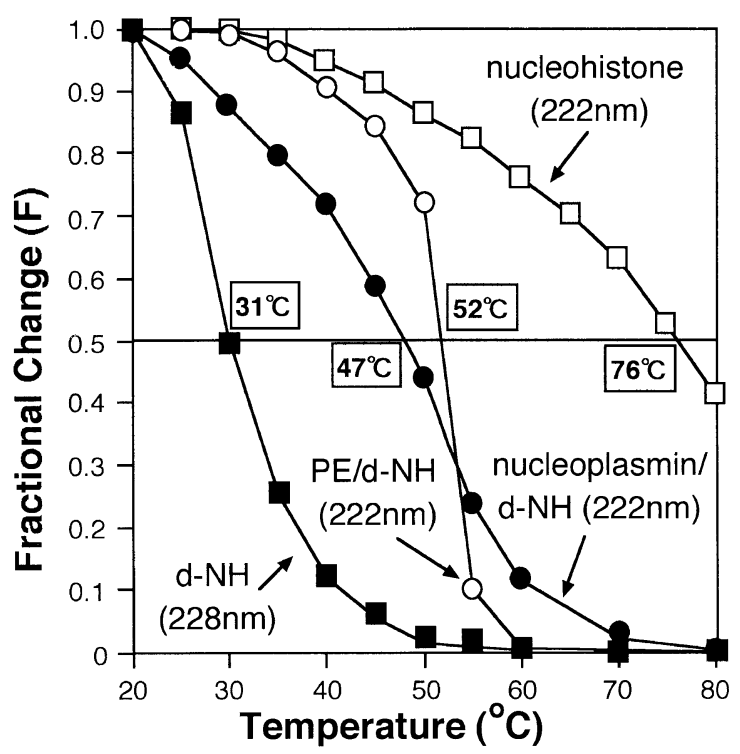

Figure 7. Thermal transitional curves of nucleohistone, d-NH, nucleoplasmin/d-NH, and PE/d-NH mixtures. The plots, respectively, represent the fractional change from previous structures to a random coil conformation as measured by $\mathrm{CD}$ spectroscopy at $222 \mathrm{~nm}$ (nucleohistone, nucleoplasmin/d-NH, and $\mathrm{PE} / \mathrm{d}-\mathrm{NH}$ ) and $228 \mathrm{~nm}$ (d-NH). ㅁ, nucleohistone at $222 \mathrm{~nm}$; $\mathbf{n}$, d-NH at $228 \mathrm{~nm}$; -, nucleoplasmin/d-NH at $222 \mathrm{~nm} ; \mathrm{O}, \mathrm{PE} / \mathrm{d}-\mathrm{NH}$ at $222 \mathrm{~nm}$.

the sperm decondensation. ${ }^{18,19}$ Our present study is focused on evaluating the effect of nucleoplasmin on a 
nucleosome structure. In this study, we used a nuclease digested-nucleohistone (d-NH) as a model complex of DNA and histone. The d-NH showed a low $\alpha$-helicity and aggregated. The results of CD spectra and turbidity measurements of d-NH at different temperatures suggest that the decrease in the $\alpha$-helicity of histones is not due to the high turbidity but rather due to conformational changes brought on by the aggregation (Figure 2). The structure of histone in d-NH is obviously different from that of nucleohistone. The thermal stability of d-NH $\left(T_{\mathrm{m}}=31^{\circ} \mathrm{C}\right)$ was significantly lower than that of nucleohistone $\left(T_{\mathrm{m}}=76^{\circ} \mathrm{C}\right)$ (Figure 2a-II). The $\alpha$-helical conformation of histone is likely important for the stability of the nucleosome structure. The CD studies of d-NH at various $\mathrm{pH}$ conditions and salt concentrations suggest that an electrostatic anion binding to histones seems to be one of the important factors for the aggregation of d-NH. The results of urea and guanidine $\mathrm{HCl}$ denaturation of d-NH also indicate that ionic interactions and/or hydrogen bonds could critically contribute to the stabilization of the d-NH structure. These results suggest that d-NH has unique properties and is a suitable model complex to demonstrate the effect of nucleoplasmin on the nucleosome assembly process.

Nucleoplasmin was found to increase the $\alpha$-helicity of the histones in d-NH and to stabilize their structures (Figures 5 and 6). PE also increased the $\alpha$-helicity of the histone but the activity became weaker than that of nucleoplasmin. BSA did not affect the conformation of d-NH, and PK decreased the $\alpha$-helicity. The time course $\mathrm{CD}$ analysis and turbidity measurements of mixtures of nucleoplasmin/d-NH and PE/d-NH indicated that nucleoplasmin most significantly affected the nucleosome structure. Nucleoplasmin has a characteristic amino acid sequence that contains many glutamic acid residues, which form a polyglutamic acid tract. $^{20,21}$ These results suggest that the polyglutamic acid tract of nucleoplasmin is important for the function of nucleoplasmin. The thermal stability of mixtures, nucleoplasmin $/ \mathrm{d}-\mathrm{NH}\left(T_{\mathrm{m}}=47^{\circ} \mathrm{C}\right)$ and $\mathrm{PE} / \mathrm{d}-\mathrm{NH}$ $\left(T_{\mathrm{m}}=52^{\circ} \mathrm{C}\right)$, suggested that PE stabilized the structure of d-NH more effectively than nucleoplasmin. This contradiction could be explained in two ways: 1) the structure of nucleoplasmin is lost at a higher temperature and the binding to d-NH decreased, since nucleoplasmin functions as a highly ordered protein structure, and 2) The volume of PE added to the d-NH solution was adjusted to the same acidic amino acid residues as that of nucleoplasmin. In the nucleoplasmin molecule, less than 20 acidic residues form the polyglutamic acid tract, which may interact with histones, and the other 25 acidic residues (Glu; 15, Asp; 10) in the protein may be involved in protein folding. PE can interact with the basic amino acids of histones. Thus, PE stabilized the $\alpha$-helical conformation more effectively than nucleoplasmin at high temperatures.

Based on the experimental data, we suggest the role of nucleoplasmin in the nucleosome structure. DNA and histone easily aggregate by non-specific ionic interactions and/or hydrogen bond interactions, and the $\alpha$-helical structure is lost by this aggregation. Nucleoplasmin promotes the nucleosome assembly by inhibiting the aggregation. Although the $\alpha$-helix of the H3 and $\mathrm{H} 4$ histones is not necessary for nucleosome assembly, ${ }^{32}$ the conformation of the histones including the $\alpha$-helix seems to be important for the interaction with DNA in the nucleosome. ${ }^{30,31}$ The $\alpha$-helical structure of the core histones seems to be critical for the assembly of highly regulated and super ordered nucleosome structures. Nucleoplasmin not only promotes the nucleosome assembly by transferring histones to DNA in the initial step, but also inhibits non-specific interactions between the histones and DNA. Nucleoplasmin may effectively promote nucleosome assembly as a molecular chaperone by inhibiting aggregation and protecting the $\alpha$-helical structures of the histone core. There are many factors involved in nucleosome assembly. ${ }^{34-37}$ Nucleoplasmin promotes nucleosome assembly, but other factors regulate this process in vivo. Many of the other factors are ATP-dependent chaperones. Generally, ATP-dependent chaperones are more effective and specific than nucleoplasmin which is not an ATP-dependent chaperone. Nucleoplasmin was found to support the activity of the transcriptional factors. ${ }^{38}$ Nucleoplasmin is an abundant protein in nuclei that seems to play an important role in supporting the activity of the other factors by inhibiting the aggregation of the DNA and histones, and by maintaining the $\alpha$-helical conformation of the histones. These findings define the novel activities of the nucleoplasmin in promoting nucleosome assembly.

Acknowledgment. We thank Dr. Hynda, K. Kleinman (NIDCR/NIH, Bethesda, Maryland. USA) for critical reading of the manuscript. This work was supported by the Grants-in-Aid for Scientific Research from the Ministry of Education, Culture, Sports, Science and Technology of Japan (No. 11694114, No. 11450359 , No. 10555327 , and No. 13132201) and also by Hokkaido Foundation for the Promotion of Scientific and Industrial Technology (Hokscitec).

\section{REFERENCES}

1. R. D. Kornberg and J. O. Thomas, Science, 184, 865 (1974). 
2. K. Finch, L. C. Lutter, D. Rhodes, R. S. Brown, B. Rushton, M. Levitt, and A. Klug, Nature, 269, 29 (1977).

3. K. E. Van Holde, J. R. Allen, K. Tatchell, W. O. Weischet, and D. Lohr, Biophys. J., 32, 271 (1980).

4. K. Luger, A. W. Mader, R. K. Richmond, D. F. Sargent, and T. J. Richmond, Nature, 389, 868 (1997).

5. H. H. Ohlenbusch, B. M. Olivera, D. Tuan, and N. Davidson, J. Mol. Biol., 25, 299 (1967).

6. D. R. Burton, M. J. Butler, J. E. Hyde, D. Phillips, C. J. Skidmore, and J. O. Walker, Nucleic Acid Res., 5, 3643 (1978).

7. D. E. Olins, P. N. Bryan, R. E. Harrington, W. E. Hill, and A. L. Olins, Nucleic Acids Res., 4, 1911 (1977).

8. C. L. F. Woodcock and L. L. Y. Frado, Cold Spring Harbor Symp. Quant. Biol., 42, 43 (1978).

9. R. A. Laskey, A. D. Mills, and N. R. Morris, Cell, 10, 237 (1977).

10. R. A. Laskey, B. M. Honda, A. D. Mills, and J. T. Finch, $N a-$ ture, 275, 416 (1978).

11. W. C. Earnshaw, B. M. Honda, J. O. Thomas, and R. A. Laskey, Cell, 21, 373 (1980).

12. K. Ohsumi and C. Katagiri, Dev. Biol., 148, 295 (1991).

13. A. Philpott, G. H. Leno, and R. A. Laskey, Cell, 65, 659 (1991).

14. T. Itoh, K. Ohsumi, and C. Katagiri, Develop. Growth. Differ, 35, 59 (1993).

15. P. Rice, T. Graduno, T. Itoh, C. Katagiri, and J. Ausio, Biochemistry, 34, (1995).

16. H. Chen, B. Li, and J. L. Workman, EMBO J., 13, 380 (1994).

17. N. Moreau, N. Angelier, R. A. Bonnanfant-Jais, P. Gounou, and P. Kubisz, J. Cell. Biol., 103, 683 (1986).

18. K. Iwata, K. Hozumi, T. Itoh, N. Sakairi, S. Tokura, C. Katagiri, and N. Norio, Int. J. Biol. Macromol., 20, 171 (1997).

19. K. Iwata, K. Hozumi, A. Iihara, M. Nomizu, N. Sakairi, and N. Norio, Int. J. Biol. Macromol., 26, 95 (1999).

20. C. Dingwall, S. M. Dilworth, S. J. Black, S. E. Kearsey, L. S. Cox, and R. A. Laskey, EMBO J., 6, 69 (1987).
21. T. R. Burglin, I. W. Mattaj, D. D. Newmeyer, R. Zeler, and E. M. De Robertis, Genes Dev., 1, 97 (1987).

22. L. Sealy, M. Cotton, and R. Chalkley, EMBO J., 5, 3305 (1986).

23. L. Klevan and N. Schumaker, Nuc. Acid. Res., 10 (21), 6809 (1982).

24. Y. Goto, N. Takahashi, and L. F. Anthony, Biochemistry, 29, 3480 (1990).

25. Y. Goto and S. Aimoto, J. Mol. Biol., 218, 387 (1991).

26. J. T. Finch and A. Klug, Proc. Natl. Acad. Sci. U.S.A., 3, 1897 (1976).

27. J. Widom and A. Klug, Cell, 43, 207 (1985).

28. H. Zentgraf and W. W. Franke, J. Cell. Biol., 99, 272 (1984).

29. G. Arents, R. W. Burlingame, Bi-C. Wang, W. E. Love, and E. N. Moudrianakis, Proc. Natl. Acad. Sci. U.S.A., 88, 10148 (1991).

30. G. Arents and E. N. Moudrianakis, Proc. Natl. Acad. Sci. U.S.A., 90, 10489 (1993).

31. M. Suzuki, Proc. Natl. Acad. Sci. U.S.A., 89, 8726 (1992).

32. L. Freeman, H. Kurumizaka, and A. P. Wolffe, Proc. Natl. Acad. Sci. U.S.A., 93, 12780 (1996).

33. J. A. Kleinschimidt, A. Seiter, and H. Zentgraf, EMBO J., 9(6), 1309 (1990).

34. P. D. Kaufman, R. Kobayashi, and B. Stillman, Genes Dev, 11(3), 345 (1997).

35. Y. Ishimi, J. Hirosumi, W. Sato, K. Sugasawa, S. Yokota, F. Hanaoka, and M. Yamada, Eur. J. Biochem., 142, 431 (1984).

36. M. Bulger, T. Ito, R. T. Kamakaka, and J. T. Kadonaga, Proc. Natl. Acad. Sci. U.S.A., 92, 11726 (1995).

37. J. C. Hansen, K. E. vanHolde, and D. Lohr, J. Biol. Chem., 266, 4276 (1991).

38. P. P. Walter, J. A. Owen-Hughes, J. Cote, and J. L. Workman, Mol. Cell. Biol., 15(11), 6178 (1995).

39. Y. H. Chen, J. T. Yang, and K. H. Cau, Biochemistry, 13, 3350 (1974). 